\title{
ist \\ Notas introdutórias ao pragmatismo clássico
}

Renato Rodrigues Kinoughi

\author{
Peirce conduziu a James e James conduziu a Dewey \\ e o resultado foi uma teoria da verdade \\ indutiva e experimental (Savery, 1939).
}

A palavra pragmatismo é um daqueles termos filosóficos polissêmicos, para os quais o primeiro passo na análise costuma ser o levantamento de sua origem etimológica. Recorrendo à etimologia, aprendemos que o termo vem do grego prámatiké, significando "conjunto de regras ou fórmulas que regulam as cerimônias oficiais ou religiosas" (Weiszflog, 1998, p. 1679). Então o pragmatismo filosófico, originalmente, deveria ser entendido como a consideração das questões filosóficas a partir de determinadas regras ou fórmulas reguladoras. Não obstante, há outro significado segundo o qual essa doutrina consistiria na "consideração das coisas a partir de um ponto de vista prático" (Weiszflog, 1998, p. 1679). Nesse sentido, um indivíduo pragmático é aquele que não se prende de antemão a princípios ideológicos ou fundamentações metafísicas, mas sim lida com as questões tendo em vista suas conseqüências práticas. Essas duas definições, conquanto não sejam mutuamente excludentes, acabam informando duas visões diferentes de filosofia: uma mais normativa e outra mais utilitária. Aqui nosso trabalho consistirá, em sua maior parte, em contrastar as concepções filosóficas dos fundadores do pragmatismo - a saber, Charles Sanders Peirce, William James e John Dewey - tendo em vista pôr em evidência suas diferenças mais significativas. Todavia, existe um ponto que justifica dizer que há uma base comum a todos eles. O pragmatismo pode ser sucintamente entendido como sendo, de certo modo, um expediente - que por sua vez significa um "meio de sair de um embaraço, de vencer uma dificuldade, de lograr bom êxito em alguma coisa" (Weiszflog, 1998, p. 922). Por um lado, o expediente certamente tem sua utilidade prática; e, por outro, trata-se de uma regra ou de uma fórmula para lidar com questões que demandam uma solução. No final das contas, um expediente transmite a idéia de um método para abordar os problemas. Desse modo, para apreendermos o sentido completo da palavra pragmatismo, temos sim que considerar o papel da utilidade prática, mas não podemos esquecer que o pragmatismo se coloca, antes de tudo, como uma questão de método. 


\section{l A idéía de Peirce}

Comecemos por explicitar o pragmatismo em sua formulação original. Sem meias palavras, o pragmatismo nasce como uma teoria relativa ao modus operandi da ciência, pois se refere essencialmente ao auxílio prestado por certas fórmulas ou regras na prática científica. De fato, a primeira aparição do pragmatismo em forma escrita, embora o termo não tenha sido empregado, acontece em uma série de seis ensaios coletivamente intitulados de Ilustrações da lógica da ciência. A propósito, se examinarmos a trajetória intelectual de Peirce, veremos que a maior parte de sua vida foi dedicada a questões ligadas à ciência, tanto no campo teórico como no experimental. No campo teórico, ele investigava questões principalmente ligadas à matemática e à lógica. No que tange à experimentação, Peirce indica que praticamente "morou em um laboratório desde a idade de seis anos até bem depois da maturidade e, tendo toda uma vida relacionada com experimentalistas, sempre teve a sensação de compreendê-los e de ser por eles compreendido" (Peirce, 2000b [1905], p. 282). Cabe remarcar que Peirce não foi apenas um filósofo bem informado em ciência. Ele foi realmente um pesquisador profissional e, com efeito, para ele o método científico oferece a maneira mais apropriada de raciocinar.

Conforme assinalam alguns críticos: "Quando vista como um todo, a filosofia de Peirce pode ser caracterizada de diferentes maneiras, mas, seja como for, deve dizerse que é uma filosofia científica" (Houser \& Kloesel, 1992, p. xxxiv). Pois bem, tratarse-ia então de alguma variante daquilo que usualmente chamamos de positivismo? Não exatamente, pois o positivismo, em linhas gerais, sustenta que somente a ciência teria importância crucial; a metafísica seria um mero palavrório sem sentido que deveria ser o quanto antes eliminado. Peirce, por sua vez, enquanto nutre uma alta estima pela ciência, não propõe o abandono da metafísica, mas antes sua reformulação, por meio da utilização do método científico. Isso é o que ele chama de "prope-positivismo" - onde o prefixo prope significa algo como largo, amplo - isto é, um tipo de positivismo não sectário que, ao invés de repudiar o que é inobservável, diga-se a metafísica como um todo, procura lançar as luzes da ciência sobre ela, para esclarecê-la:

Na minha opinião, a atual condição infantil da filosofia [...] é devido ao fato de que durante este século [xIx] ela foi principalmente alvo da dedicação de homens que não se educaram em laboratórios e salas de dissecção e, conseqüentemente, não foram estimulados pelo verdadeiro Eros científico (Peirce, 1998 [1898], p. 29).

Mas é bom deixar claro que o tal Eros científico estimularia desinteressadamente a aquisição e o aumento do conhecimento. Em verdade, a filosofia, auxiliada pela 
ciência, não teria como tarefa precípua resolver questões vitais de ordem prática, mas ampliar, por assim dizer, nosso espaço intelectual. O pragmatismo de Peirce é de natureza intelectualista; e se há referência à prática, trata-se de prática racional - isto é, relativa à otimização da economia do raciocínio proporcionada pela lógica. Esse ponto é a chave para o entendimento do pensamento peirceano. É preciso notar que a validade de um argumento assegura que retiremos conclusões verdadeiras a partir de premissas verdadeiras. Caso contrário, nada nos previne de retirarmos conclusões falsas apesar da verdade das premissas. O efeito prático de um argumento válido é não nos deixar resvalar em erros. Assim, questões de lógica têm um aspecto muitíssimo prático para o estudioso da ciência.

O empreendimento de esclarecer a filosofia, por meio da lógica empregada na ciência, perpassa toda a obra peirceana. Todavia, já é hora de colocar em cena um outro autor pragmatista, a saber, o psicólogo e filósofo William James, que interpretava o pragmatismo de uma maneira diferente, o que por sinal causava certos constrangimentos, de modo que as reflexões posteriores de Peirce são, em larga medida, uma reação às idéias do psicólogo. A esse propósito, há uma célebre passagem em que Peirce dizia que sua criança (o pragmatismo) havia sido raptada (cf. Talisse, 2000); e dali em diante, para circunscrever sua definição original, ele a rebatizou de pragmaticismo - um nome "feio o suficiente para ficar a salvo de raptores" (Peirce, 2000b [1905], p. 287). Nesse ínterim, Peirce passa a dar muito mais detalhes sobre o que o pragmatismo é, e, mais ainda, esforça-se sobremaneira para dizer o que seu pragmatismo nãoé. Mas, para compreendermos esse debate, faz-se necessário conhecer a interpretação de James, caso contrário, as reflexões posteriores de Peirce ficariam mais ou menos no vazio.

\section{A interpretação de James}

James e Peirce se conheceram ainda jovens, por volta de 1861, dentro do círculo acadêmico da Harvard Scientific School. O calouro William logo percebeu que o veterano Charles era "um colega muito inteligente, com uma grande personalidade, bem independente, embora um tanto violenta" (Skrupskelis \& Berkeley, 1995, p. 43). Logo os dois rapazes tornaram-se amigos, a despeito de acentuadas diferenças de formação. Peirce era bem do tipo acadêmico, crescido em uma família de scholars. Por sua vez, James era um burguês, crescido em um ambiente literário, ${ }^{\mathbf{1}}$ que optou por dedicar-se

1 A título de ilustração diga-se que James era afilhado de Ralph Waldo Emerson. Para se imaginar um pouco da atmosfera intelectual em que William James cresceu, basta ler algum romance de seu irmão mais novo, o famoso ficcionista Henry James. 
à ciência, especificamente às áreas de medicina, biologia e história natural. Como curiosidade, diga-se que, em 1865, aos vinte três anos, James participou de uma expedição científica à Amazônia, fazendo parte, por oito meses, da equipe do naturalista Louis Agassiz (cf. Menand, 2001). Mas ao regressar da expedição, o jovem reconheceu que não tinha vocação para o trabalho de naturalista e acabou por formar-se em medicina.

Convém assinalar que James também foi um "homem de ciência”, embora de uma maneira diferente de Peirce. A principal diferença, que terá conseqüências profundas para o desenvolvimento de suas respectivas visões filosóficas, é que a formação de James, em medicina, biologia e psicologia - e não em física e matemática - fez com que ele tivesse uma perspectiva mais nominalista a respeito da ciência, em oposição ao realismo de Peirce. Por nominalismo, grosso modo, entende-se a tese de que os termos gerais são agrupamentos lingüísticos de instâncias particulares; portanto, quando a ciência fala, por exemplo, acerca de Massa (com M maiúsculo), na verdade agrupa-se sobre uma palavra propriedades que os corpos (com c minúsculo) apresentam. Por sinal, a idéia de tipo (espécime) ideal e da imutabilidade das espécies, no campo da biologia, estava em declínio depois da popularização de Darwin, que significava um avanço do nominalismo nas áreas biológicas. O nominalismo de James fez com que seu modo de olhar a ciência fosse mais relativizado, mas isso não quer dizer que James tivesse menos apreço pela ciência.

A propósito, James era um dos integrantes do Metaphysical Club, o sarau filosófico em que ocorreram as primeiras discussões acerca do pragmatismo, por volta de 1870, cujo nome tem um certo tom pomposamente irreverente (cf. Menand, 2001). E muito certamente ele leu os artigos da coleção Ilustrações de Peirce, datados de $1877^{-}$ 1878, onde aparece a máxima pragmática, mesmo que não se tenha dado um nome explícito a ela. Por mais de vinte anos aqueles debates ficaram, por assim dizer, latentes; isto é, o pragmatismo não foi de imediato reconhecido pela comunidade intelectual. Isso não quer dizer, entretanto, que idéias pragmatistas não circulassem sub-repticiamente. Com efeito, a psicologia veiculada por James em seu The principles of psychology (Princípios de psicologia) de 1890, já delimita aquilo que podemos chamar de pragmatismo jamesiano.

É nesse livro, mais precisamente no seu capítulo final, intitulado "Verdades necessárias e os efeitos da experiência”, que aparece sua mais concisa definição de ciência natural, a qual concatena vários pontos importantes, cada um deles merecendo ser discutido separadamente. Mas, para não perder o sentido do todo, ela será apresentada de uma só vez, e depois discutiremos os pontos principais. Nas palavras de James:

A ciência rende expressões que, dados os lugares e tempos, podem ser traduzidas em valores reais, ou interpretadas como porções definidas no interior do caos 
que cai sob nossos sentidos. Ela se torna um guia prático de nossas expectativas tanto quanto proporciona prazer teórico. Mas eu não vejo como alguém com senso dos fatos poderia chamar isso de resultados imediatos da experiência [tal como concebia Herbert Spencer]. Toda concepção científica é, antes de qualquer coisa, uma "variação espontânea" no cérebro de alguém. Para cada concepção que se prove útil e aplicável existem milhares de outras que perecem devido a sua falta de valor. Sua gênese é estritamente aparentada com aquelas inspirações poéticas, ou com as máximas de sabedoria, das quais as variações cerebrais também são a fonte. Mas enquanto a poesia e a sabedoria (como a ciência dos antigos) são sua própria razão de ser, e não vão muito além disso, as concepções científicas devem provar seu valor sendo verificáveis. Tal teste é a causa de sua preservação, não de sua produção (James, 1983 [189o], p. 1232-3).

Nota-se primeiramente a noção de ciência como uma espécie de ferramenta lingüística que organiza os dados dos sentidos. A ciência fornece expressões que servem para traduzir ou interpretar as inúmeras experiências sensoriais. Essa formulação abre espaço para uma visão mais psicologista da ciência, que será retomada mais adiante. Mas, até aqui, não há ainda uma grande diferença entre a concepção de James e aquela de Peirce, pois este último também considerava que as sensações experimentadas por vários cientistas são de fato individuais. Para ambos, todavia, o que há de distintivo, na ciência, é que ela promove um acordo intersubjetivo, por meio da expressão de leis que organizam as inúmeras sensações individuais.

Em segundo lugar, já se nota como o pragmatismo jamesiano está associado ao praticalismo e, com efeito, isso está contido plenamente em sua visão de ciência. Ele pensa as teorias científicas do ponto de vista de sua utilidade prática, como guias de nossas ações no mundo. É bem verdade que James também se refere ao deleite teórico proporcionado pela ciência, seu aspecto contemplativo A inspiração poética, por exemplo, é aparentada com a inspiração científica, mas o que realmente distingue a ciência é sua relação de correspondência com o mundo, enquanto que a poesia, no entender de James, bastaria por si mesma.

Sem dúvida, a versão jamesiana do pragmatismo sustenta aquela segunda interpretação da palavra prámatiké: a consideração das coisas sob um ponto de vista prático. No ensaio intitulado "Concepções filosóficas e resultados práticos" de 1898, James inicia sua exposição dizendo que "[Peirce] é um dos pensadores contemporâneos mais originais; e eu acredito, cada vez mais, que o princípio do praticalismo - ou pragmatismo, como ele dizia, na primeira ocasião em que eu o ouvi falar disso, em Cambridge, no começo de 1870 - é a chave ou bússola com a qual podemos manter nossos passos no caminho certo" (James, 1992 [1898], p. 1079). Com efeito, há que se destacar duas 
coisas. Primeiro, que é manifesto que a palavra pragmatismo, denominando estritamente uma doutrina filosófica, foi uma invenção de Peirce. Em segundo lugar, nota-se que James, quando chama essa doutrina de praticalismo, já agrega ao debate um pouco de sua própria interpretação. Nesse ínterim, aparece um certo acento anti-intelectualista, que anuncia a tendência de expandir o pragmatismo em direção às chamadas questões vitais da existência humana. Entre essas questões encontram-se aquelas de natureza religiosa, sobre as quais James se propõe a aplicar o "princípio de Peirce". Grosso modo, defende que os efeitos da experiência religiosa sobre um indivíduo justificam a vida religiosa dessa pessoa. Não haveria assim motivo para descartar-se sumariamente, por exemplo, a crença na existência de Deus, visto que muitas pessoas efetivamente vivenciam os efeitos de uma tal crença. O que se nota é que o pragmatismo de James às vezes parece soar como uma espécie de existencialismo utilitarista.

\section{A regonstrução de John Dewey}

John Dewey (1859-1952) ocupou um lugar privilegiado dentro do pensamento norteamericano. Vinte anos mais novo que Peirce e James, Dewey se tornou a principal figura do pragmatismo no século xx. Na verdade, Peirce e James, que faleceram antes da primeira guerra mundial, ainda eram homens do século xIX. Mas os noventa e três anos vividos por Dewey permitiram-lhe ser espectador das duas guerras mundiais que transformaram a paisagem política do mundo contemporâneo. Além disso, sua origem social imprimiu-lhe características distintas em relação a Peirce e James. John Dewey representava a classe média norte-americana da época. Ele era filho de um pequeno comerciante e, de fato, se não fosse a influência de sua mãe, Lucina, provavelmente não teria formação universitária (cf. Dewey, 1939, p. 4). Quando criança, Dewey engajara-se nas mais triviais responsabilidades domésticas, tal como acontecia com os amigos de sua idade. Nesse contexto, a educação formal era vista como desconectada da realidade.

A percepção de que as partes mais importantes de sua própria educação, antes de entrar na universidade, foram obtidas fora da sala de aula, desempenhou um grande papel em seu trabalho educacional, no qual grande importância é dada, tanto em teoria quanto na prática, às atividades ocupacionais, sendo essas as mais efetivas abordagens para uma educação genuína e disciplina intelectual pessoal (Dewey, 1939, p. 9).

Após graduar-se na Universidade de Vermont, Dewey trabalhou como professor secundarista no estado da Pensilvânia, mas pouco tempo depois iniciou sua pós-gradua- 
ção na recém-inaugurada Universidade John Hopkins, por volta de 188o. Lá ele encontrou um círculo intelectual que incluía professores tais como George Sylvester Morris - que se dedicava à divulgação do idealismo alemão em sua versão hegeliana -, James McKeen Cattell - que se tornou célebre por suas contribuições na área de testes antropométricos - e G. Stanley Hall - aluno de William James e um dos mais importantes professores de psicologia no início do século xx. Além disso, Dewey também teve a oportunidade de cursar as disciplinas de lógica científica ministradas por Peirce - curso que, por sinal, foi praticamente a única atividade docente de Peirce.

Em 1884, Dewey foi convidado a lecionar na Universidade de Michigan. Era o início de uma carreira profissional que ainda incluiria uma breve passagem de apenas um ano pela Universidade de Minnesota. A seguir, Dewey dedicou aproximadamente dez anos à Universidade de Chicago, onde compunha o departamento junto com nomes dignos de menção, tais como James H. Tufts, James R. Angell e George Herbert Mead. A esse propósito, William James (2002) reconhecia em Dewey e na chamada Escola de Chicago uma das mais importantes vertentes da então nascente filosofia americana. Mas em razão de atritos com o reitor dessa universidade, o filósofo acabou se transferindo para a Universidade de Columbia, onde trabalhou por mais trinta e cinco anos, até sua aposentadoria em 1939. Ou seja, em sua longa e produtiva vida, Dewey trabalhou como professor universitário por aproximadamente 55 anos. Para um relato detalhado de sua trajetória no ambiente universitário norte-americano, uma boa fonte de consulta é o ensaio biográfico escrito por Jane M. Dewey (1939), filha do filósofo.

Dewey também iniciou sua filosofia sob o impacto das teorias evolucionárias do século xIx, mais particularmente, o darwinismo. $\mathrm{O}$ enfoque naturalista do pensamento de Dewey certamente encontrou ressonância primeiramente na obra de William James, cujo Princípios de psicologia, acentuadamente darwinista, foi a obra singular que mais o impressionou e influenciou. Como atesta Jane Dewey:

A influência de James sobre a teoria do conhecimento de Dewey não aconteceu graças ao [livro] Pragmatismo, que apareceu depois que a teoria de Dewey havia se formado, outrossim, pelos capítulos dos Princípios de psicologia que tratavam da concepção, da discriminação e da comparação, e do raciocínio. Dewey freqüentemente recomendava esses capítulos a seus estudantes como a melhor introdução ao que há de essencial em uma teoria pragmática do conhecimento, mais do que o Pragmatismo (Dewey, 1939, p. 23).

O fato de Dewey indicar os Princípios sugere um sentimento que às vezes perpassa alguns leitores de James, pois, na realidade, o Pragmatismo é um livro fraco em certos aspectos. Certamente é o livro que fez a fama do movimento pragmatista, mas, a 
julgar pela reação de Peirce (que procurava distanciar-se dele), somado ao fato de que o próprio James sentiu a necessidade de reapresentar suas idéias em The meaning of truth ( $O$ significado da verdade), percebe-se que alguma coisa não estava bem. Uma das coisas mais interessantes da obra de Dewey é que ele, ao ocupar o lugar privilegiado de "herdeiro" do pragmatismo, tinha plena consciência das diferenças de enfoque entre Peirce e James. Segundo Dewey:

Peirce era acima de tudo um lógico; enquanto James era um educador e um humanista, que desejava forçar o grande público a reconhecer que certos problemas, certos debates filosóficos, tinham uma importância real para a humanidade, porque as crenças que eles colocam em jogo levam a modos de conduta bastante diferentes. Se essa importante distinção não for apreendida, fica impossível entender a maioria das ambigüidades e dos erros pertencentes ao período posterior do movimento pragmático (Dewey, 1981 [1931], p. 46).

Essa percepção de que o pragmatismo de Peirce é de natureza lógica, enquanto James divulgou um pragmatismo humanista, possibilita Dewey sintetizar um novo tipo de pragmatismo que, em uma linguagem atualizada, entrelaça valores cognitivos, éticos e sociais. O pragmatismo originalmente imaginado por Peirce era um método de esclarecer conceitos ou representações concernentes a termos teóricos presentes na ciência. Ou seja, tratava-se de uma questão de otimização do raciocínio, dizendo respeito mais a valores cognitivos. Por sua vez, James interpreta essas noções em um outro contexto, aplicando-as a temas muito mais abrangentes, especialmente a questões de natureza ética e religiosa. Nesse caso, o pragmatismo começa a lidar com a esfera dos valores éticos e sociais, indo além daquilo que Peirce originalmente imaginara.

Certamente a máxima peirceana de considerar os efeitos sensíveis dos conceitos intelectuais funcionava perfeitamente dentro da esfera dos valores cognitivos, mas, apesar de toda a boa vontade de James, gerava inquietação na esfera dos valores sociais. No tocante a Dewey, apesar de não repudiar a esfera dos valores sociais (muito ao contrário, tinha-os em alta conta), ele percebia que havia algo que precisava ser esclarecido:

Mas James devotou-se primariamente aos aspectos morais dessa teoria, ao embasamento que ela dá ao "melhorismo" e ao idealismo moral, e às conseqüências que seguem dela no tocante ao valor sentimental e às ligações de vários sistemas filosóficos, particularmente às implicações destrutivas para o racionalismo monista e para o absolutismo em todas suas formas. Ele nunca procurou desenvolver uma teoria completa das formas ou "estruturas" e das operações lógicas que se fundam nessa concepção. $\mathrm{O}$ instrumentalismo é uma tentativa de estabelecer 
uma teoria lógica precisa dos conceitos, dos juízos e das inferências em suas diversas formas, considerando primeiramente como o pensamento funciona na determinação experimental de suas conseqüências futuras. Significa dizer que o instrumentalismo tenta estabelecer distinções universalmente reconhecidas e regras de lógica, derivando-as da função reconstrutiva ou mediativa atribuída à razão. Objetiva-se constituir uma teoria das formas gerais de concepção e de raciocínio, e não deste ou daquele juízo particular ou conceito relacionado com seu próprio conteúdo, ou com suas implicações particulares (Dewey, 1981 [1931], p. 51).

Quando faz considerações desse tipo, Dewey soa muito próximo a Peirce. Aqui, os valores cognitivos estão em sua plena expressão e há um certo realismo, no sentido oposto ao nominalismo, de modo que a preocupação é com a generalidade do processo de investigação. Mas há uma diferença fundamental entre Dewey e Peirce. Este último, fortemente orientado por sua formação em matemática, pensa suas estruturas de maneira praticamente platônica. Essencial para sua teoria era uma característica, por assim dizer, topológica das estruturas triádicas. O cerne da questão consiste na defesa de que quaisquer relações $\mathrm{n}$-ádicas podem ser reduzidas a combinações triádicas, mas as triádicas não podem ser reduzidas a combinações diádicas (Peirce, 2000a [1885]). Sendo assim, Peirce defendia que as "estruturas" deveriam ser consideradas segundo um esquema de categorias sempre triádicas. Essa idéia atravessa toda a filosofia peirceana e chega a tomar contornos quase místicos - há algo de pitagorismo no ar.

Dewey, por sua vez, tinha uma abordagem mais naturalista do que normativa, o que na visão de Peirce era insuficiente. Em carta a Dewey, Peirce diz: "Você propõe substituir uma ciência normativa [a lógica], que a meu ver é a grande carência de nossa época, por uma "história natural" do pensamento ou da experiência [...] Não penso que uma coisa tal como história natural possa responder àquela enorme carência" (Peirce apud Pihlström, 2004, p. 43). Ou seja, apesar de ambos estarem interessados em questões da lógica da investigação, estando então ocupados com valores cognitivos, suas abordagens diferiam. Mas para percebermos isso, precisamos conhecer mais de perto o caráter naturalista do pragmatismo de Dewey.

Como dito anteriormente, as teorias evolucionárias tiveram grande impacto nos trabalhos de Dewey. Ele considerava as habilidades humanas em continuidade com a história natural das espécies. Por isso, mesmo a lógica - que costuma ser considerada uma disciplina normativa - deve ser abordada levando em consideração contornos biológicos:

A lógica é uma teoria naturalista. O termo "naturalista" tem vários significados. Tal como empregado aqui significa, por um lado, que não há quebra de continuidade entre as operações de investigação e as operações biológicas e físicas. 
Essa "continuidade", por outro lado, significa que as operações lógicas crescem a partir de atividades orgânicas, sem serem idênticas àquilo do qual emergem [...] . A lógica em questão é também naturalista no sentido da observabilidade, no sentido ordinário da palavra, das atividades de investigação. Concepções derivadas de uma faculdade mística da intuição ou qualquer outra coisa tão oculta a ponto de não estar aberta à inspeção e à verificação públicas (tais como aquelas puramente psíquicas, por exemplo) estão excluídas (Dewey, 1938, p. 19).

Nota-se claramente que Dewey não admitia certas transcendências que, no fundo, significam um corte qualitativo entre o pensamento e a natureza, mas que, no entanto, estão para além de qualquer confirmação ou refutação empírica. A lógica de Dewey é imanente à evolução e não se furta do dever de submeter-se ao escrutínio científico. Todavia, a evolução biológica não é a única circunstância que delimita a lógica:

Uma ambigüidade da palavra "naturalista" é que ela pode ser entendida como envolvendo uma redução do comportamento humano ao comportamento de primatas, amebas, ou elétrons e prótons. Mas o homem é naturalmente um ser que vive em associação com outros, em comunidades possuidoras de linguagens e, portanto, usufruindo uma cultura transmitida. A investigação é um modo de atividade que é socialmente condicionado e que possui conseqüências culturais [...]. Portanto, a concepção naturalista da lógica, que subjaz à posição aqui assumida, é um naturalismo cultural. Nem a investigação, nem sequer o mais abstrato conjunto formal de símbolos podem escapar da matriz cultural na qual eles vivem, movem-se e têm sua existência (Dewey, 1938, p. 19).

Ora, isso vai mais na linha de uma antropologia filosófica, na qual se leva em consideração uma série de fatores tais como o curso da evolução da espécie humana, as primeiras comunidades e, posteriormente, a formação das civilizações, em especial a grega, donde nasce uma ciência contemplativa e, mais adiante, o Renascimento e o despontar do conhecimento de natureza tecnológica.

Nesse ponto, Dewey começa a dar ênfase aos valores sociais que circunscreveram a história e o desenrolar da atividade científica. O filósofo entende que uma das mais profundas heranças a respeito da natureza do conhecimento científico adveio da divisão de classes própria do mundo grego entre escravos e cidadãos, com a forte separação entre as atividades manuais e as contemplativas. Mas embora tais condicionantes tenham de fato deixado de existir, há uma inércia que mantém a atividade científica atada aos valores antigos: é por isso que Dewey (1959c) defende que devemos reconstruir a filosofia para adequar nossas concepções teóricas ao mundo contemporâneo. 
Um assunto da máxima importância, e que apenas mencionaremos aqui, é o fato de que a cultura científica é transmitida pela educação. Ora, por essa via chega-se àquilo que é considerado por muitos como o cerne da obra deweyana: sua teoria pedagógica. Em obras como os famosos Teoria da vida moral (1964), Como pensamos (1959a [1910]) e Democracia e educação (1959b [1916]), fica manifesto que a questão dos valores sociais impregna sua pedagogia.

Todos os adultos adquiriram, no decurso de sua experiência e educação, certas medidas do valor de várias espécies de experiências. Aprenderam a considerar como coisas moralmente boas a honestidade, a amabilidade, a perseverança e a lealdade; e como valores estéticos certos clássicos da literatura, da pintura, da música e assim por diante. Não somente isso; mas aprenderam também certas regras para esses valores: a regra áurea para a moral; a harmonia, o equilíbrio, etc., a proporcionalidade de elementos nas obras estéticas; a objetividade, a clareza, a sistematização, nos trabalhos intelectuais. Tais princípios são tão importantes, porque equivalem a padrões para aferir o valor das novas experiências, que os pais e os professores sempre tendem a ensiná-los diretamente aos jovens (Dewey, 1959b [1916], p. 257).

Finalmente chegamos ao último ponto que queríamos assinalar. Não só os valores têm um lugar destacado na visão deweyana sobre a educação, como fica evidente que o filósofo aponta claramente valores cognitivos, sociais e estéticos que perpassam a educação como um todo. Objetividade, clareza e sistematicidade nos trabalhos intelectuais são critérios que focalizam valores cognitivos; honestidade, amabilidade, perseverança e lealdade consistem em valores éticos e são orientados pela regra áurea da moral; e, finalmente, harmonia, equilíbrio e proporcionalidade de elementos são avaliações de valores estéticos.

Nas próximas páginas, oferecemos a tradução do ensaio "The development of American pragmatism", no qual Dewey expõe com precisão as idas e vindas do pragmatismo em seu período clássico. As notas introdutórias aqui apresentadas apenas pontuam certas partes centrais do texto, mas não se comparam ao escrutínio realizado por Dewey. Como já mencionado, se houve alguém que dispôs de uma posição privilegiada para discorrer sobre o pragmatismo como movimento filosófico, esse alguém foi John Dewey. ↔

\section{Renato Rodrigues Kinoughi}

Professor Adjunto do Centro de Ciências Naturais e Humanas, Universidade Federal do ABC, Brasil. renato.kinouchi@ufabc.edu.br 


\section{REFERÊNGIAS BIBLIOGRÁFICAS}

Dewey, J. Logic: the theory of inquiry. New York: Holt, Rinehart and Winston, 1938. . Como pensamos. Tradução H. C. Campos. São Paulo: Companhia Editora Nacional, 1959a [1910]. . Democracia e educação. Tradução G. Rangel \& A. Teixeira. São Paulo: Companhia Editora Nacional, 1959b [1916].

. Reconstrução em filosofia. Tradução A. P. Carvalho. São Paulo: Companhia Editora Nacional,1959c. Teoria da vida moral. Tradução L. G. Carvalho. São Paulo: Ibrasa, 1964.

.The development of American pragmatism. In: McDermotт, J. J. (Org.). The philosophy ofJohn Dewey. Chicago: The University of Chicago Press, 1981 [1931]. p. 411-58.

Dewey, J. M. Biography of John Dewey. In: Schilpp, P. A. (Ed.). The philosophy of John Dewey. Chicago: Northwestern University, 1939. p. 3-45 (The Library of Living Philosophers, 1).

Guinsburg, J. (Ed.). Semiótica. São Paulo: Perspectiva, 2000. (Coleção Estudos, 46).

Houser, N. (Ed.). The essential Peirce: selected philosophical writings. Bloomington: Indiana University Press, 1998 [1898].v. 2: 1893-1913.

Houser, N. \& Kloesel, G. (Ed.). The essential Peirce: selected philosophical writings. Bloomington: Indiana University Press, 1992. v. 1: 1867-1893.

James, W. The principles of psychology. Cambridge, Mass.: Harvard University Press, 1983 [1890].

. Philosophical conceptions and practical results. In: MYers (Org.). William James writings 1878-1899. New York: The Library of America, 1992 [1898]. p. 1077-97.

. The Chicago school. In: Green, C. D. (Org.). Classics of the history of psychology, 2002 [1904]. Disponível em: 〈http://psychclassics.yorku.ca/James/chicago.htm>. Acess. em: 10 out. 2007.

McDermotт, J. J. (Org.). The philosophy of John Dewey. Chicago: The University of Chicago Press, 1981.

Menand, L. The Metaphysical Club: a story of ideas in America. New York: Farrar, Straus \& Giroux, 2001.

Misak, G. (Ed.). The Cambridge companion to Peirce. New York: Cambridge University Press, 2004.

Myers (Org.). William James writings 1878-1899. New York: The Library of America, 1992.

Peirce, C. S. Philosophy and the conduct of life. In: Houser, N. (Ed.). The essential Peirce: selected philosophical writings. Bloomington: Indiana University Press, 1998 [1898]. v. 2: 1893-1913, p. 27-41.

. Tríades. Tradução J. T. G. Neto. In: Guinsburg, J. (Ed.). Semiótica. São Paulo: Perspectiva, $2000 a$ [1885].p. 9-18. (Coleção Estudos, 46).

. O que é o pragmatismo. Tradução J. T. G. Neto. In: Guinsburg, J. (Ed.). Semiótica. São Paulo: Perspectiva, 2000b [1905].p. 283-99. (Coleção Estudos, 46).

Pinlström, S. Peirce's place in the pragmatist tradition. In: Misak, C. (Ed.). The Cambridge companion to Peirce. New York: Cambridge University Press, 2004. p. 27-57.

SAvery, W. The significance of Dewey's philosophy. In: Schilpp, P. A. (Ed.). The philosophy of John Dewey. Chicago: Northwestern University, 1939. p. 481-513 (The Library of Living Philosophers, 1).

Schilpp, P. A. (Ed.). The philosophy of John Dewey. Chicago: Northwestern University, 1939. (The Library of Living Philosophers, 1).

Skrupskelis, I. K. \& Berkeley, E. M. (Org.). The correspondence of William James. Charlottesville: University Press of Virginia, 1995. v. 4 .

Talisse, R. B. How James kidnapped Peirce. Streams of William James, 2, 1, p. 7-10, 2000.

Weiszflog, W. (Ed.). Michaelis: moderno dicionário da língua portuguesa. São Paulo: Melhoramentos, 1998. 